\title{
Modern outcomes with modified PCNL
}

\begin{abstract}
Introduction: In this study, we update our experience using modified PCNL (mPCNL), a technique that incorporates standard PCNL instruments through a smaller 24 French (Fr) sheath.

Methods: We retrospectively reviewed 209 patients that underwent mPCNL from January 2015 to July 2016. 183 patients had complete data and were included in the analysis. Patient demographics, stone-free rates, measures of postoperative pain and complications were recorded. Results from $\mathrm{mPCNL}$ were compared with a recent series of standard PCNL at our institution.

Results: Average stone burden was $3.14 \mathrm{~cm}$. The overall stone-free rate for our cohort was $96.7 \%$. 134 patients had stone burdens $\geq 2 \mathrm{~cm}$ and the mean stone burden among these patients was $3.76 \mathrm{~cm}$. Compared to 52 patients undergoing standard PCNL (with a $30 \mathrm{Fr}$ sheath), stone-free rates were similar $(96.2 \%$ vs. $91.5 \%, p=0.20)$ but operating room times for $\mathrm{mPCNL}$ were shorter (105 minutes vs. 162 minutes, $\mathrm{p}<0.001)$ and blood loss was less ( $77 \mathrm{ml}$ vs. $105 \mathrm{ml}, \mathrm{p}=0.02)$. Use of ketorolac was lower $(1.6 \mathrm{mg}$ vs. $22.8 \mathrm{mg}, \mathrm{p}<0.001)$ while the morphine equivalents requirements were similar for $\mathrm{mPCNL}$ patients. Blood transfusion rate was $1.6 \%$ for our entire PCNL cohort.
\end{abstract}

Conclusion: $\mathrm{mPCNL}$ combines the benefits of using standard PCNL instruments for efficient clearance of large stone burdens while achieving the improved pain scores, decreased blood loss and shorter hospital stays commonly observed with miniaturized procedures.

Keywords: percutaneous nephrolithotomy, nephrolithiasis, lithotripsy
Volume 5 Issue 5 - 2017

Timothy Y Tran, Egor Parkhomenko, Julie

Thai, Kyle Blum, Mantu Gupta

Department of Urology, Icahn School of Medicine at Mount Sinai, USA

Correspondence: Timothy Y Tran, Department of Urology, Icahn School of Medicine at Mount Sinai, 425 W. 59th Street, 4th Floor New York, NY I0019, USA, Tel 78I-888-8I84, Email timothy.y.tran@gmail.com

Received: October 22, 2017 | Published: November 07, 2017
Abbreviations: PCNL, percutaneous nephrolithotomy; mPCNL, modified percutaneous nephrolithotomy; Fr, french; $\mathrm{ml}$, milliliters

\section{Introduction}

Percutaneous nephrolithotomy (PCNL) is the treatment of choice for patients with renal calculi $\geq 2 \mathrm{~cm}$ as well as larger lower pole calculi. ${ }^{1,2}$ The armamentarium of specialized rigid and flexible nephroscopes and powerful lithotripters allow for greater stone-free rates in the treatment of patients with large stone burdens . ${ }^{3}$. However, in comparison to shockwave lithotripsy and ureteroscopy, PCNL is associated with greater morbidity, particularly with respect to bleeding risk. This is attributed to the creation of a nephrostomy tract with subsequent tract dilation resulting in shearing of renal parenchyma and bleeding. ${ }^{4}$ As such, percutaneous surgery using smaller tracts has been explored as a means to limit the morbidity of PCNL. An assortment of options ranging from micro-, to ultramini-, to mini-PCNL have been described..$^{5-7}$ Recent series have demonstrated improvements in bleeding risk, ${ }^{8}$ postoperative pain scores ${ }^{9}$ and hospital length of stay ${ }^{10}$ compared with standard PCNL. However, despite these benefits, technical limitations apply. Smaller access tracts require miniaturized instruments, precluding the use of many efficient stone fragmentation and retrieval devices routinely used in standard PCNL. Therefore, while reported stone-free rates are generally high, these studies are often limited to patients with stone burdens between 10-20 mm.,

Modified PCNL ( $\mathrm{mPCNL}$ ) was originally described as a case series of 52 patients in $2013 .{ }^{11}$. This technique, which uses a 24 French (Fr) access sheath with standard PCNL instruments (after removal of the outer rigid nephroscope sheath), was proposed to combine the benefits of miniaturized and standard PCNL's. Intraoperative blood loss, postoperative pain and length of stay were low while stone-free rates, even for stones $\geq 2 \mathrm{~cm}$ were high.$^{11}$. In the time since, our group has predominantly used $\mathrm{mPCNL}$ when performing percutaneous renal stone surgery. Here, we report our updated results with this technique.

\section{Patients and methods}

\section{Patient selection, data acquisition and analysis}

We retrospectively reviewed cases using mPCNL from 2014 to present. Patients were excluded from analysis if they had concomitant ureteropelvic junction obstruction, calyceal diverticula, or ureteral strictures that required treatment at the time of PCNL. This series represents an updated experience of a single surgeon (MG) at a tertiary referral medical center. Stone burden was calculated based upon the maximum stone diameter for each stone treated within a renal unit. Procedure time was recorded from the time the case began (insertion of cystoscope for placement of retrograde catheter) to its end (securing the dressing to the patient flank). Post-operative morphine equivalents and ketorolac dose was determined upon review of hospital charts. Stone-free status was defined as the absence of visualized stone fragments on intraoperative nephroscopy and fluoroscopy and on postoperative imaging at one month (computed tomography or renal ultrasonography). Statistical significance was determined using Student's t-test and Chi-Squared test where appropriate.

\section{Description of technique}

After induction with general anesthesia, the patient is transitioned to the prone position with appropriate support on a split-leg table. Flexible cystoscopy is performed and a0.038 inch guide wire is advanced into the ureter of interest under direct vision. After fluoroscopic confirmation, we typically advance and deploy the 
Accordion device (Percsys Corp, Palo Alto, CA) at the ureteropelvic junction. This film-based coaxial occlusion device limits antegrade passage of stone fragments into the ureter during stone fragmentation. Retrograde pyelography is performed to characterize the calycealanatomy. A urethral catheter is then inserted for bladder drainage. Under fluoroscopic guidance, we use an $11.5 \mathrm{~cm}, 18$-gauge diamond-tipped trocar needle (Cook Medical, Bloomington, IN) for selective calyceal puncture using a triangulation technique. An angletipped Sensor wire (Boston Scientific, Marlborough, MA) is advanced into the collecting system. Once coiling of the wire is confirmed with fluoroscopy, the access needle is removed. A scalpel is then used to incise the skin adjacent to the guide wire in place. Next, an Ultraxx balloon dilating set (Cook Medical, Bloomington, IN) or Nephromax balloon dilating set (Boston Scientific, Marlborough, MA) is used to radially dilate the $24 \mathrm{Fr}$ tract. Finally, the included Amplatz $24 \mathrm{Fr}$ Teflon sheath is advanced with fluoroscopic guidance to the desired depth.

A 26F rigid nephroscope (Karl Storz, El Segundo, CA) can be used for all components of the procedure. To allow for passage through the smaller nephrostomy tract, the outer sheath is removed and the 22 Fr instrument is advanced. No additional modifications are required and all standard graspers and lithotripters may be used through the scope. Of note, with the outer sheath removed, care should be taken during introduction of instruments through the working channel. Once the instruments are within the tract, they may be used as normal without further concern except for avoiding excessive torque. Flexible nephroscopy is readily performed with standard flexible cystoscope. In cases of a concomitant ureteral calculus, antegrade ureteroscopy and basket extraction with or without laser lithotripsy can be performed to achieve stone-free status. When appropriate, nephrostomy tubes and/or ureteral stents should be placed at the completion of the case. Routine follow-up care should remain consistent with standard institutional PCNL protocols.

\section{Results}

There were 209 patients undergoing mPCNL during the study period (January 2015 to July 2016). Of these, 183 had complete data and were included in the analysis. Examination of patient demographics and operative characteristics is noted in Table 1. The average patient age in this cohort was 55.9 years. Approximately half of all patients were male $(51.4 \%)$ and half female $(48.6 \%)$. Average body mass index (BMI) was 28.3. Of all patients, 129 were categorized as overweight by BMI (70.8\%) and within this group, $25(13.7 \%)$ were obese, $19(10.5 \%)$ severely obese and $13(7.1 \%)$ morbidly obese. The average stone burden was $3.14 \mathrm{~cm}$ and 134 patients $(73.6 \%)$ had stone burdens greater than $2 \mathrm{~cm}$. Among this group, the average stone burden was $3.76 \mathrm{~cm}$. Stone-free rates were $96.7 \%$ overall and $96.2 \%$ for patients with stone burden $\geq 2 \mathrm{~cm}$. Of the 182 patients, $170(93.4 \%)$ were discharged home on the first post-operative day. Three patients $(1.6 \%)$ received blood transfusions post-operatively. We also compared our results using $\mathrm{mPCNL}$ for patients with stone burden $\geq 2 \mathrm{~cm}$ to our most recent cohort of patients that underwent standard PCNL (using a 30-French coaxial dilator and sheath) for stone burden $\geq 2 \mathrm{~cm}$ (Table 2). While there was no difference in mean stone burden $(3.76 \mathrm{~cm}$ vs. $3.67 \mathrm{~cm}, \mathrm{p}=0.80)$, there was a significantly shorter operating room time (105 vs. 162 minutes, $\mathrm{p}<0.001)$ and lower estimated blood loss ( $77 \mathrm{ml}$ vs. $105 \mathrm{ml}, \mathrm{p}=0.02)$. Stone-free rates were similar between the two groups, with the success rate for mPCNL slightly higher $(96.2 \%$ vs. $91.5 \%, \mathrm{p}=0.20)$. Ketorolac use was lower among patients undergoing mPCNL (1.6 mg vs. $22.8 \mathrm{mg}$, $\mathrm{p}<0.001)$. Length of hospital stay was lower for the mPCNL group, but this difference did not reach statistical significance (1.3 days vs. 1.79 days, $\mathrm{p}=0.15$ ).

Table I Demographic and Operative Data for Modified PCNL

\begin{tabular}{ll}
\hline & Value \\
\hline $\mathrm{N}$ & 182 \\
Male / Female & Male $94(51.4 \%)$ \\
Stone Burden (mm) & Female 89 (48.6\%) \\
$\%$ Stone Burden $>2 \mathrm{~cm}$ & 31.5 \\
Stone-Free (\%) & $74 \%$ \\
Procedure time (min) & $96.7 \%$ \\
EBL (ml) & 99.8 \\
Stent Placed & 71.8 \\
Nephrostomy Tube Placed & $98(53.8 \%)$ \\
Average Post-operative Morphine Equivalents $(\mathrm{mg})$ & $176(96.7 \%)$ \\
Average Post-operative Ketorolac dose (mg) & 24.2 \\
Length of Hospital Stay (days) & 1.8 \\
Patients with LOS $€$ I day & 1.28 \\
Transfusion Rate & $170(93.4 \%)$ \\
\hline
\end{tabular}

\section{Discussion}

In 1978, Dr. Arthur Smith reported the placement of the first ante grade ureteral stent. ${ }^{12}$ From that point forward, Dr. Smith, combined with a select group of pioneers in Urology and Radiology proceeded to develop the backbone of modern percutaneous renal surgery. Dilating instruments were developed and refined to minimize injury to the ureteropelvic junction and collecting system. ${ }^{13}$ Specialized wires and balloon dilators were constructed for the procedure. In 1982, Smith and colleagues reported an $87 \%$ stone-free rate for 63 stones treated by PCNL. ${ }^{14}$ In addition to the high stone-free rate reported, the early days of PCNL required only a few days of postoperative convalescence in the hospital and complications occurred in just $12 \%$ ( 3 of 25 ) of patients. ${ }^{14}$ This report marked a tremendous improvement when compared to the staggering morbidity of the contemporary stone surgeries, which were wrought with 1-3 week hospital stays and complication rates as high as $45 \% .^{15,16}$

From these beginnings, advances in nephroscope optics, access techniques and lithotripters have culminated with the modern PCNL. ${ }^{17}$ The standard armamentarium now includes a 20-22 Fr rigid nephroscope (with a 24-26 Fr sheath), a 16 Fr flexible nephroscope and a selection of ultrasonic, pneumatic and laser lithotripters. Combined with an assortment of baskets and graspers, these tools have helped drive improvements in PCNL efficiency while decreasing its morbidity. ${ }^{18}$ In an effort to further decrease the morbidity of PCNL, investigators have explored further miniaturization of the percutaneous access tract. ${ }^{19}$ Improvements in pain scores, transfusion rates and hospital length of stay have been noted on some series, ${ }^{8-10}$ but these results have not been consistently reported..$^{20}$ Also, the narrower tracts require smaller nephroscopes and preclude the use of many stone fragmentation and extraction devices employed as part of standard PCNL. While these smaller tracts may yield benefits for patient recovery, the lesser visualization due to decreased irrigation and outflow from the smaller tract and scope size, combined with limitations in the use of a flexible nephroscope to inspect all calyces and the difficulty with removing stone fragments through the smaller tract often limits the use of these procedures to patients with smaller stones involving fewer calyces. ${ }^{21}$ 
Table 2 Comparing Outcomes of $\mathrm{mPCNL}$ and Standard PCNL for Patients with Stone Burden $\geq 2 \mathrm{~cm}$

\begin{tabular}{llll}
\hline & Modified PCNL $>$ 2 cm & Standard PCNL & p-value \\
\hline \hline $\mathrm{N}$ & 134 & 42 & - \\
Stone burden $(\mathrm{mm})$ & 37.6 & 36.7 & 0.80 \\
Stone Free & $96.2 \%$ & $91.5 \%$ & 0.20 \\
OR time (min) & 105 & 162 & $<0.001$ \\
EBL (ml) & 77 & 115 & 0.02 \\
Stent placed & $76(56.7 \%)$ & $19(45 \%)$ & 0.19 \\
Nephrostomy tube placed & $131(98 \%)$ & $37(88 \%)$ & 0.008 \\
Morphine Equivalents (mg) & 25.3 & 20.5 & 0.39 \\
Ketorolac (mg) & 1.6 & 22.8 & $<0.001$ \\
Length of Hospital Stay (days) & 1.3 & 1.79 & 0.15 \\
\hline
\end{tabular}

Table 3 Comparison of mPCNL with Other Series of Standard and Miniaturized PCNL

\begin{tabular}{|c|c|c|c|c|c|}
\hline & Modified PCNL & CROES Global stud ${ }^{26}$ & BAUS registry ${ }^{25}$ & Mini-PCNL ${ }^{24}$ & Ultramini-PCNL ${ }^{5}$ \\
\hline $\mathrm{N}$ & 182 & 5803 & 980 & 1368 & 36 \\
\hline Tract Size & $24 \mathrm{Fr}$ & $\geq 27 \mathrm{Fr}$ (in $75 \%$ ) & - & $16 \mathrm{Fr}$ & $\mathrm{II}-\mathrm{I} 3 \mathrm{Fr}$ \\
\hline Age Mean (SD) & $55.9(14.0)$ & $49.2(15.6)$ & 54 & 46 & $48.2(15.7)$ \\
\hline BMI Mean (SD) & $28.3(6.3)$ & $26.8(5.9)$ & - & - & - \\
\hline Stone Burden (mm) & 31.4 & - & $\begin{array}{l}29 \% \text { Staghorn } \\
29 \%>2 \mathrm{~cm} \\
34 \% 1-2 \mathrm{~cm} \\
8 \%<1 \mathrm{~cm}\end{array}$ & I.7 - $6.4 \mathrm{~cm}$ (No mean provided) & 14.9 \\
\hline Stone-Free & $96.7 \%$ & $75.7 \%$ & $80 \%$ & $82 \%$ & $88.9 \%$ \\
\hline Nephrostomy Tube & $96.7 \%$ & $91.2 \%$ & $76 \%$ & $100 \%$ & $2.7 \%$ \\
\hline Stent & $53.8 \%$ & $42.7 \%$ & $23 \%$ & $100 \%$ & $8.3 \%$ \\
\hline Transfusion & $1.6 \%$ & $5.7 \%$ & $2.5 \%$ & $1.6 \%$ & $0 \%$ \\
\hline
\end{tabular}

In contrast, $\mathrm{mPCNL}$ allows for use of all of the standard instruments for PCNL while preserving many benefits of the miniaturized procedures. It has been consistently demonstrated that the use of larger access tracts increases the risk of significant bleeding. ${ }^{22,23}$ Using a $24 \mathrm{Fr}$ sheath instead of a $30 \mathrm{Fr}$ sheath results in an access tract that is $36 \%$ smaller. As expected, this yielded an improvement in intraoperative blood loss when $\mathrm{mPCNL}$ was compared with our standard PCNL series ( $77 \mathrm{ml}$ vs. $115 \mathrm{ml}, \mathrm{p}=0.02)$. Additionally, the transfusion rate for mPCNL was $1.6 \%$ ( 3 of 182 patients), which is identical to the transfusion rate reported in a recent series of 1368 patients undergoing mini-PCNL through a $16 \mathrm{Fr}$ sheath (Table 3) ${ }^{24}$. Finally, in comparison to recent reports from large, multicenter databases using standard PCNL, the transfusion rate for $\mathrm{mPCNL}$ was lower $(1.6 \%$ versus $2.5 \%$ and $5.7 \%){ }^{25,26}$

Importantly, among patients with larger stone burdens, stone-free rates remained high with $\mathrm{mPCNL}$. Previously, our group reported successful stone clearance in 18 of 18 patients with stone burden $\geq 2$ $\mathrm{cm} .{ }^{11}$ Here, among the 134 patients with stone burden $\geq 2 \mathrm{~cm}$ (mean stone burden $=3.76 \mathrm{~cm}$ ), stone-free rates were $96.7 \%$ (Table 2). Even among patients with a stone burden $\geq 5 \mathrm{~cm}$, the stone free rate was $88.9 \%$ ( 24 of 27 patients). Whereas miniaturized procedures may be limited to patients with smaller stones, $\mathrm{mPCNL}$ has yielded high stonefree rates for large stone burdens. An additional benefit of the smaller sheath is increased spontaneous expulsion of smaller stone fragments through the sheath with irrigation. This is a result of two factors. First, the smaller cross-sectional area of the narrower access sheath yields increased irrigation inflow and outflow velocity. Second, removal of the outer nephroscope sheath allows for more space within the access sheath for stone fragments to pass (Figure 1). Thus smaller fragments can be expulsed simply by irrigation instead of time-consuming stone grasping or use of suctioning instruments. This was not a phenomenon observed during standard PCNL with the $30 \mathrm{Fr}$ sheath. The expulsion using irrigation improves the efficiency of stone removal and likely contributed to the decrease in operating time that we observed when comparing $\mathrm{mPCNL}$ with standard PCNL at our institution (105 min vs. $162 \mathrm{~min}, \mathrm{p}<0.001)$
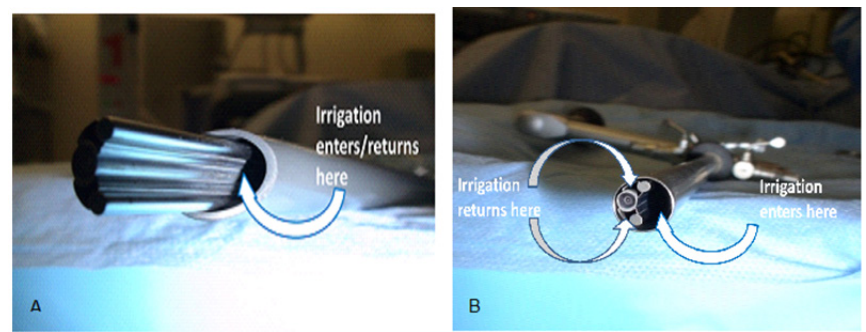

Figure I Comparison of space for irrigation inflow and outflow using modified approach. Note the increased space for irrigation outflow with removal of the outer sheath $(A)$ compared with room for outflow with the outer sheath attached (B).

The limitations of this study are its retrospective nature and that it is a single-surgeon series. The retrospective nature limited the assessment of postoperative pain. During the time period where standard PCNL was commonly performed at our institution, patients were typically treated with opioid narcotics and non-steroidal anti-inflammatory drugs. Since the routine use of $\mathrm{mPCNL}$, postoperative pain control was primarily provided by opioid narcotics. Thus, while it appears that postoperative pain is less as there is no significant difference in morphine equivalents and ketorolac use is much lower (Table 2), this cannot be definitively concluded. Finally, the ideal comparison for outcomes and complications between these techniques would be a 
multi-center randomized controlled trial evaluating miniature versus standard and mPCNL. ${ }^{27}$

\section{Conclusion}

Modified PCNL successfully blends the efficient stone extraction of standard PCNL with the lower bleeding risk, transfusion rates and postoperative pain seen with miniaturized procedures.

\section{Conflicts of interest}

There are no conflicts of interest for any authors.

\section{Funding}

None.

\section{References}

1. Assimos D, Krambeck A, Miller NL, et al. Surgical Management of Stones:American Urological Association/Endourological Society Guideline, PART II. J Urol. 2016;196(4):1153-1160.

2. Türk C, Petř́k A, Sarica K, et al. EAU Guidelines on Interventional Treatment for Urolithiasis. Eur Urol. 2016;69(3):475-482.

3. Hyams ES, Shah O. Percutaneous nephrostolithotomy versus flexible ureteroscopy/holmium laser lithotripsy: cost and outcome analysis. $J$ Urol. 2009;182(3):1012-1017.

4. Michel MS, Trojan L, Rassweiler JJ. Complications in percutaneous nephrolithotomy. Eur Urol. 2017;51(4):899-906.

5. Desai J, Zeng G, Zhao Z, et al. A novel technique of ultra-minipercutaneous nephrolithotomy:introduction and an initial experience for treatment of upper urinary calculi less than $2 \mathrm{~cm}$. Biomed Res Int. 2013;2013:490793.

6. Desai MR, Sharma R, Mishra S, et al. Single-step percutaneous nephrolithotomy (microperc): the initial clinical report. $J$ Urol. 2011;186(1):140-145.

7. Jackman SV, Docimo SG, Cadeddu JA, et al. The mini-perc technique:a less invasive alternative to percutaneous nephrolithotomy. World J Urol. 1998;16(6):371-374.

8. Cheng F, Yu W, Zhang X, et al. Minimally invasive tract in percutaneous nephrolithotomy for renal stones. J Endourol. 2010;24(10):1579-1582.

9. Knoll T, Wezel F, Michel MS, et al. Do patients benefit from miniaturized tubeless percutaneous nephrolithotomy? A comparative prospective study. J Endourol. 2010;24(7):1075-1079.

10. Mishra S, Sharma R, Garg C, et al. Prospective comparative study of miniperc and standard PNL for treatment of 1 to $2 \mathrm{~cm}$ size renal stone. BJU Int. 2011;108(6):896-899.

11. Lipsky MJ, Shapiro EY, Cha DY, et al. Modified-PCNL without modified instruments: a description of technique. J Endourol. 2013;27(6):684 687.
12. Smith AD, Lange PH, Miller RP, et al. Introduction of the Gibbons ureteral stent facilitated by antecedent percutaneous nephrostomy. $J$ Urol. 1978;120(5):543-544.

13. Smith AD. A personal perspective on the origins of endourology and the endourological society. J Endourol. 2002;16(10):705-708.

14. Castaneda-Zuniga WR, Clayman R, Smith A, et al. Nephrostolithotomy:percutaneous techniques for urinary calculus removal. J Urol. 2002;167(2 Pt 2):849-853.

15. Carpiniello VL, Hanno PM, Malloy TR, et al. Management of simple ureterolithotomy closure. Urology. 1977;10(4):310-311.

16. Furlow WL, Bucchiere JJ. The surgical fate of ureteral calculi: review of Mayo Clinic experience. J Urol. 1976;116(5):559-561.

17. Patel SR, Nakada SY. The modern history and evolution of percutaneous nephrolithotomy. J Endourol. 2015;29(2):153-157.

18. Kamphuis GM, Baard J, Westendarp M, et al. Lessons learned from the CROES percutaneous nephrolithotomy global study. World J Urol. 2015;33(2):223-233.

19. Druskin SC, Ziemba JB. Minimally Invasive (Mini) Percutaneous Nephrolithotomy:Classification, Indications, and Outcomes. Curr Urol Rep. 2016;17(4):30.

20. Zhu W, Liu Y, Liu L, et al. Minimally invasive versus standard percutaneous nephrolithotomy: a meta-analysis. Urolithiasis. 2015;43(6):563-570.

21. Feng MI, Tamaddon K, Mikhail A, et al. Prospective randomized study of various techniques of percutaneous nephrolithotomy. Urology. 2001;58(3):345-350.

22. Wezel F, Mamoulakis C, Rioja J, et al. Two contemporary series of percutaneous tract dilation for percutaneous nephrolithotomy. $J$ Endourol. 2009;23(10):1655-1661.

23. Yamaguchi A, Skolarikos A, Buchholz NP, et al. Operating times and bleeding complications in percutaneous nephrolithotomy:a comparison of tract dilation methods in 5,537 patients in the Clinical Research Office of the Endourological Society Percutaneous Nephrolithotomy Global Study. J Endourol. 2011;25(6):933-939.

24. Hu G, Guo Z, Liu H, et al. A novel minimally invasive percutaneous nephrolithotomy technique:safety and efficacy report. Scand J Urol. 2015;49(2):174-180.

25. Armitage JN, Irving SO, Burgess NA (2012) Percutaneous nephrolithotomy in the United kingdom:results of a prospective data registry. Eur Urol. 2012;61(6):1188-1193.

26. de la Rosette J, Assimos D, Desai M, et al. The Clinical Research Office of the Endourological Society Percutaneous Nephrolithotomy Global Study: indications, complications, and outcomes in 5803 patients. $J$ Endourol. 2011;25(1):11-17.

27. Knudsen BE (2013) Editorial comment for Lisky et al. J Endourol. 2013;27(6):687. 